\title{
Affordable moisturisers are effective in atopic eczema: A randomised controlled trial
}

\author{
C Hlela, ${ }^{1} \mathrm{MB} \mathrm{ChB}, \mathrm{PhD} ;$ N Lunjani, ${ }^{1} \mathrm{MB} \mathrm{ChB} ; \mathrm{F}$ Gumedze, ${ }^{2} \mathrm{PhD} ;$ B Kakande, ${ }^{1} \mathrm{MB} \mathrm{ChB} ; \mathbf{N}$ P Khumalo, ${ }^{1} \mathrm{MB} \mathrm{ChB}, \mathrm{PhD}$ \\ ${ }^{1}$ Division of Dermatology, Red Cross War Memorial Children's Hospital and Groote Schuur Hospital, Cape Town, South Africa \\ ${ }^{2}$ Department of Statistical Sciences, Faculty of Science, University of Cape Town, South Africa
}

Corresponding author: N P Khumalo (n.khumalo@uct.ac.za)

\begin{abstract}
Background. Many patients depend on moisturisers issued by public health services in the management of atopic dermatitis (AD). Methods. In a randomised controlled trial of patients with mild to moderate AD, aged 1 - 12 years, study 1 compared aqueous cream v. liquid paraffin (fragrance-free baby oil) as a soap substitute, all patients using emulsifying ointment as moisturiser, and study 2 compared four moisturisers, emulsifying ointment, cetomacrogol, white petroleum jelly and glycerine/petroleum (proportion 1:2; 'the 1:2 moisturiser'), all using fragrance-free baby oil as soap substitute. Assessments were one quality of life and three AD severity scores, at baseline and weeks 4 , 8 and 12. Differences were compared using repeated measures of analysis of variance.

Results. In both studies (120 children randomised, 20 in each group of the two trials) disease severity scores declined with time. The only significant difference was in one AD severity score (SCORing Atopic Dermatitis) in study 1 , both at baseline and over time ( $p=0.042$ and $p=0.022$ ). The groups did not differ with regard to topical steroid use or side-effects. Itching from baby oil applied as soap was reported by four patients in the two studies, the petroleum jelly group had more dropouts than the 1:2 moisturiser group, although this was not statistically significant, and 110 patients $(91.7 \%)$ completed the trial.

Conclusions. The small sample limits generalisability, but the duration was longer than in most AD moisturiser studies. Fragrance-free baby oil as a soap substitute may be better tolerated (if irritation occurs) as a bath additive. The 1:2 moisturiser may be preferable to white petroleum jelly, but both are equivalent to cetomacrogol and emulsifying ointment. Use of accessible moisturisers could reduce the cost of managing mild to moderate $\mathrm{AD}$.
\end{abstract}

S Afr Med J 2015;105(9):780-784. DOI:10.7196/SAMJnew.8331

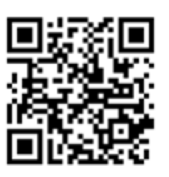

Moisturisers are cornerstones of the management of atopic dermatitis (AD). Recently published guidelines on the management of $\mathrm{AD}$ recommend that 'while the choice of moisturiser depends on individual preference, it should be safe; effective; cost-effective; and be fragrance/perfumes/additives-free. ${ }^{\left[{ }^{1]}\right]}$ In spite of these recommendations, there has been an explosion of prescription and expensive moisturisers that contain various ingredients aimed at addressing the impaired skin barrier function in $\mathrm{AD}$. These agents include prescription emollient devices and those containing ceramides and/or filaggrin breakdown products. ${ }^{[2-6]}$ Such products increase the options for treating $\mathrm{AD}$, but are expensive. There is also evidence that prescription moisturisers may not be superior to overthe counter-preparations. ${ }^{[7]}$

The prevalence of $\mathrm{AD}$ is increasing worldwide. ${ }^{[8]}$ In Cape Town, South Africa (SA), the 1-year prevalence in 13 - 14-year-old children was $8.3 \%$, increasing to $13.3 \%$ in a later study. ${ }^{[9]}$ Intractable pruritus and sleep disturbance can be severe in $\mathrm{AD}$, compromising quality of life. Consistent with international practice, potential topical irritants (e.g. from ingredients responsible for fragrance, colour and foam) should be avoided. In keeping with the SA Essential Drugs List (EDL), the most commonly used products in public health facilities are aqueous cream as a soap substitute, with emulsifying ointment and cetomacrogol as moisturisers. Recently reported impairment of the skin barrier function in healthy subjects resulting from the use of aqueous cream as a daily moisturiser has raised concern. ${ }^{[10]} \mathrm{AD}$ is the leading single contributor to the 'top ten paediatric dermatology diagnoses', which account for $>70 \%$ of patients in 12 of 19 international studies. ${ }^{[11]}$ Up to $60 \%$ of patients attending the Dermatology Clinic at Red Cross War Memorial Children's Hospital, Cape Town, SA, have
$\mathrm{AD}$, and often return with disease flares. ${ }^{[11]}$ Many of these patients use only clinic-supplied EDL moisturisers, which are not stocked by rural shops, presumably because of cost. We found no data comparing commonly used $\mathrm{AD}$ emollients with products that are routinely used and available in most homes (petroleum jelly, glycerine and baby oil). Petroleum jelly and liquid paraffin combined in a 50:50 formulation has been used locally and in the UK for AD. ${ }^{[12-14]}$ We prefer the term 'fragrance-free baby oil' to 'liquid paraffin' in order to eliminate confusion with paraffin (kerosene) that is used as fuel (for cooking/heating). Baby oil is widely used all over the world on children, including neonates. Fragrance-free baby oil is also used as a bath additive in $\mathrm{AD}$ and locally as a soap substitute for patients who are unable to tolerate aqueous cream. Glycerine (glycerol) is a good humectant ${ }^{[15,16]}$ a deterrent to its use is its sticky consistency, which we have found disappears completely when it is combined with petroleum jelly. Mixing with glycerine also reduces the shine of petroleum jelly. A proportion of glycerine/petroleum in 1:2 formulation for use as a hand cream was preferred to other unlabelled proportions by 45 of 50 hospital staff ('the 1:2 moisturiser'; unpublished data, N P Khumalo, 2012).

\section{Objective}

To compare the efficacy of easily accessible moisturisers with those currently recommended in patients with mild to moderate AD.

\section{Methods}

\section{Study design and treatment groups}

Approval to conduct the study was received from the Ethics Committee, Faculty of Health Sciences, University of Cape Town (ref: 146/2013). The trial was registered (NCT0208447). Two separate 
substudies were conducted using a randomised controlled single (assessor)-blind trial design. Patients were randomised using an automatic online enrolment system in a 1:1 ratio for study 1 or a 1:1:1:1 ratio for study 2 .

Study 1 compared aqueous cream v. baby oil as a soap substitute. All the participants used emulsifying ointment as a moisturiser. Study 2 compared four moisturiser formulations: cetomacrogrol, emulsifying ointment, glycerine/petroleum (1:2) and petroleum jelly. Study 2 participants all washed with baby oil and applied this as soap instead of aqueous cream. All the participants continued to use clinic-prescribed topical steroids during the study period, and brought back all tubes so that the amount used during the previous month could be recorded at every visit.

\section{Patients}

Patients aged 1 - 12 years were enrolled at Red Cross Children's War Memorial Hospital from 1 February 2013 to 31 June 2013. Written consent was signed by parents/guardians. All had active but stable mild to moderate atopic eczema according to the UK working party formulary criteria at screening and at baseline, ${ }^{[17]}$ and all had dry eczematous skin as the predominant feature. Patients were not eligible if they had severe atopic eczema or secondary infection, were medically unwell, or were on systemic therapy for their AD.

\section{Assessments}

Visits occurred at baseline and monthly for 3 months, and the outcomes of interest were recorded. At each of the four visits, one 'blinded' dermatologist, who was the same for all visits, did all assessments. Disease severity was asessed using the validated objective SCORing Atopic Dermatitis (SCORAD), the Nottingham Atopic Eczema Severity Score (NESS) and the Patient Oriented Eczema Measure (POEM) scores. A validated quality-of-life form using the infant's dermatitis quality of life (IDQOL) scale was completed by caregivers at each visit. The amount of topical steroids used in the preceding month was documented at each visit (i.e. number of tubes and proportion of partially used tubes). All caregivers were also requested to return all medication (received from any/all health facilities attended during the previous month). Adverse events were asked about and recorded at each visit.

\section{Statistical analysis}

Data were analysed using STATA version 13.1. ${ }^{[18]}$ With an estimate of proportions of $33 \% \mathrm{v}$. $5 \%$ and a non-inferiority margin of $5 \%$, the total sample size was 40 (20 per group for study 1 ). In the paralleldesign study, with the same parameters as above with adjustment for multiple testing, the total sample size was $44 \times 2=88$ (22 per group for study 2). We compared SCORAD/NESS/POEM and IDQOL mean scores at baseline and weeks 4,8 and 12 and summarised the findings by treatment group and time with interaction plots produced using $\mathrm{R}$ Version 3.0.2. ${ }^{[19]}$ We used repeated-measures analysis of variance which utilised all data and assessed the effect of treatment and time effect (interaction between time and treatment) using generalised estimating equations. The level of significance was set at $p<0.05$.

\section{Results}

A total of 125 children were screened and 120 randomised to provide 20 in each treatment group in the two studies (Fig. 1) (it was only noticed towards the end of the study that 20 instead of 22 participants per group had been recruited for study 2). All baseline characteristics were similar between the groups except for the objective SCORAD in study 1 , aqueous cream v. baby oil (mean (standard deviation, SD) 23.02 (11.79) v. 33.11 (16.82); $p=0.042$ ) (Table 1). One hundred and ten children completed the trial. Ten children (8.3\%) dropped out, four having complained (noted at a visit before dropping out) of itching, presumed to be from baby oil (one in study 1 and three in study 2 - one from each group except the emulsifying ointment group). All participants in the aqueous cream and emulsifying ointment group completed the study. The reason for dropping out of the trial was unknown in six patients (two from study 1 and four from study 2 - two from the cetomacrogol group and two from the petroleum jelly group) (Fig.1). Overall there was no statistical difference in the number of dropouts between groups.

Table 1. Baseline characteristics of study participants ${ }^{\star}$

\begin{tabular}{|c|c|c|c|c|c|}
\hline Study 1 & Baby oil & Aqueous cream & & & $p$-value \\
\hline Age (years), mean (SD) & $5.63(2.43)$ & $5.66(2.39)$ & & & 0.966 \\
\hline Females, $n(\%)$ & $8 / 20(40.0)$ & $9 / 17(52.9 \%)$ & & & 0.431 \\
\hline \multicolumn{6}{|c|}{ Baseline scores (mean (SD) } \\
\hline SCORAD & $23.02(11.79)$ & $33.11(16.82)$ & & & 0.042 \\
\hline POEM & $9.00(5.06)$ & $11.50(7.97)$ & & & 0.366 \\
\hline NESS & $10.20(1.96)$ & $9.50(3.25)$ & & & 0.429 \\
\hline IDQOL & $6.45(4.78)$ & $7.00(4.86)$ & & & 0.736 \\
\hline Study 2 & $\begin{array}{l}\text { Emulsifying } \\
\text { ointment }\end{array}$ & Cetomacrogol & Glycerine/petroleum jelly & Petroleum jelly & $p$-value \\
\hline Age (years), mean (SD) & $5.83(2.61)$ & $4.71(2.86)$ & $5.55(2.58)$ & $4.95(2.45)$ & 0.549 \\
\hline Females, $n(\%)$ & $20(55)$ & $17(41)$ & $19(58)$ & $17(53)$ & 0.767 \\
\hline \multicolumn{6}{|c|}{ Baseline scores, mean (SD) } \\
\hline SCORAD & $28.40(16.16)$ & $24.78(16.90)$ & $21.52(15.24)$ & $26.77(12.09)$ & 0.529 \\
\hline POEM & $9.10(4.56)$ & $9.47(6.02)$ & $9.75(7.23)$ & $11.29(7.06)$ & 0.742 \\
\hline NESS & $9.85(2.83)$ & $9.35(2.40)$ & $9.25(3.64)$ & $10.00(3.35)$ & 0.856 \\
\hline IDQOL & $7.25(5.84)$ & $7.23(4.48)$ & $7.35(6.75)$ & $6.76(3.72)$ & 0.989 \\
\hline
\end{tabular}




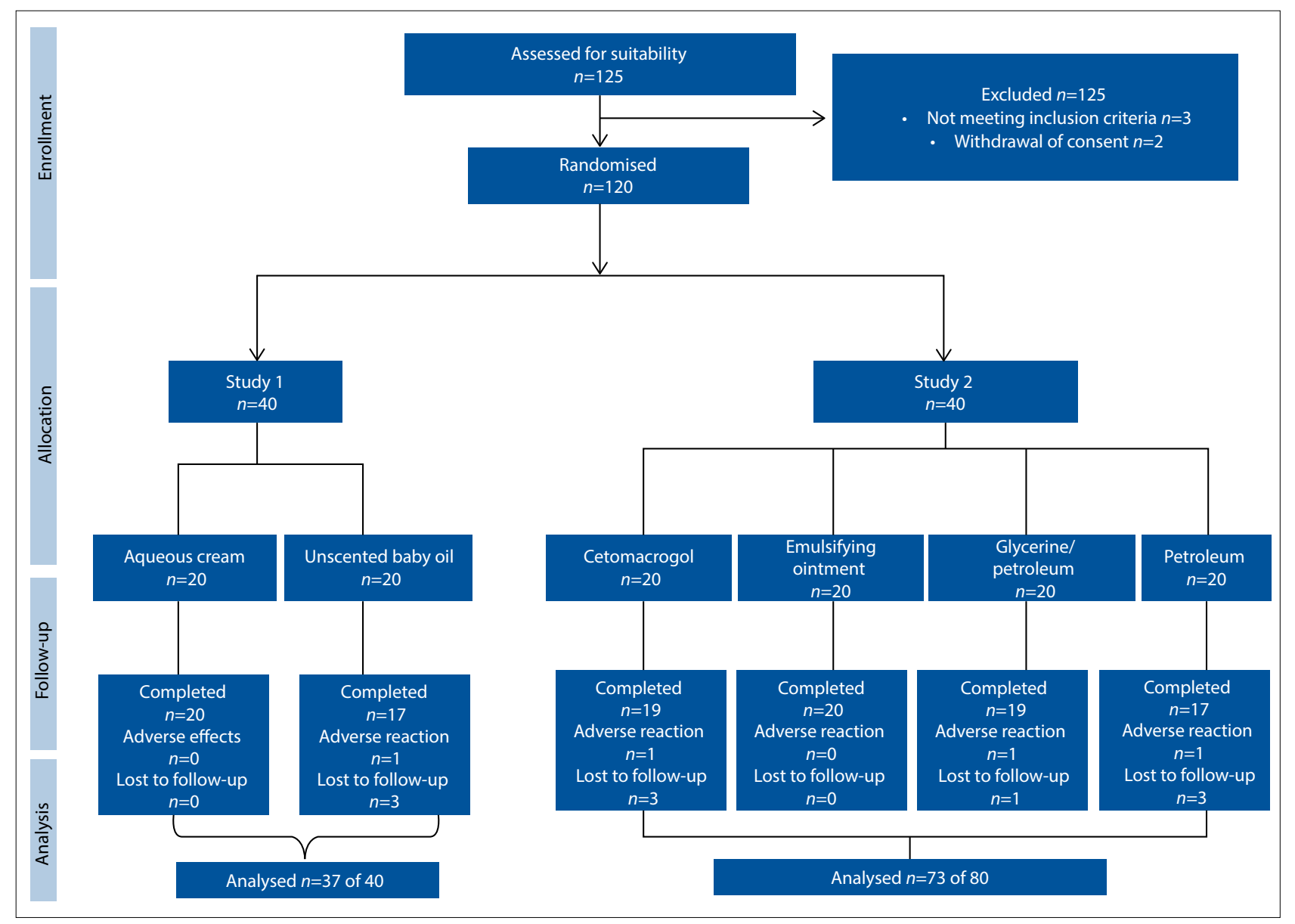

Fig. 1. Flow diagram depicting the overall study design.

All mean scores decreased over time. In study 1 , scores were similar except for the objective SCORAD, both at baseline and at the end of the study ( $p=0.022$ ) (Fig. 2). In study 2, all mean scores tended to decline over time, but there were no differences in all treatments compared with emulsifying ointment $(p=0.529)$ (Fig. 3). Furthermore, the IDQOL index did not change significantly from baseline in either study ( $p=0.736$ for study 1 and $p=0.989$ for study 2 ). There was no statistical difference in the amount of topical steroids (of various strengths) used between groups for either study (Fig. 3). Overall, there was no difference in adverse effects (itching) between groups (Fig. 1).

\section{Discussion}

Three separate disease severity scores were used in this trial to determine consistency of the results. It is interesting that overall there were no differences in severity scores between the groups from baseline and over time in any of the scores except SCORAD in study 1 (Fig. 2). However, this difference in the objective SCORAD was present both at baseline and over time and is therefore unlikely to be the result of

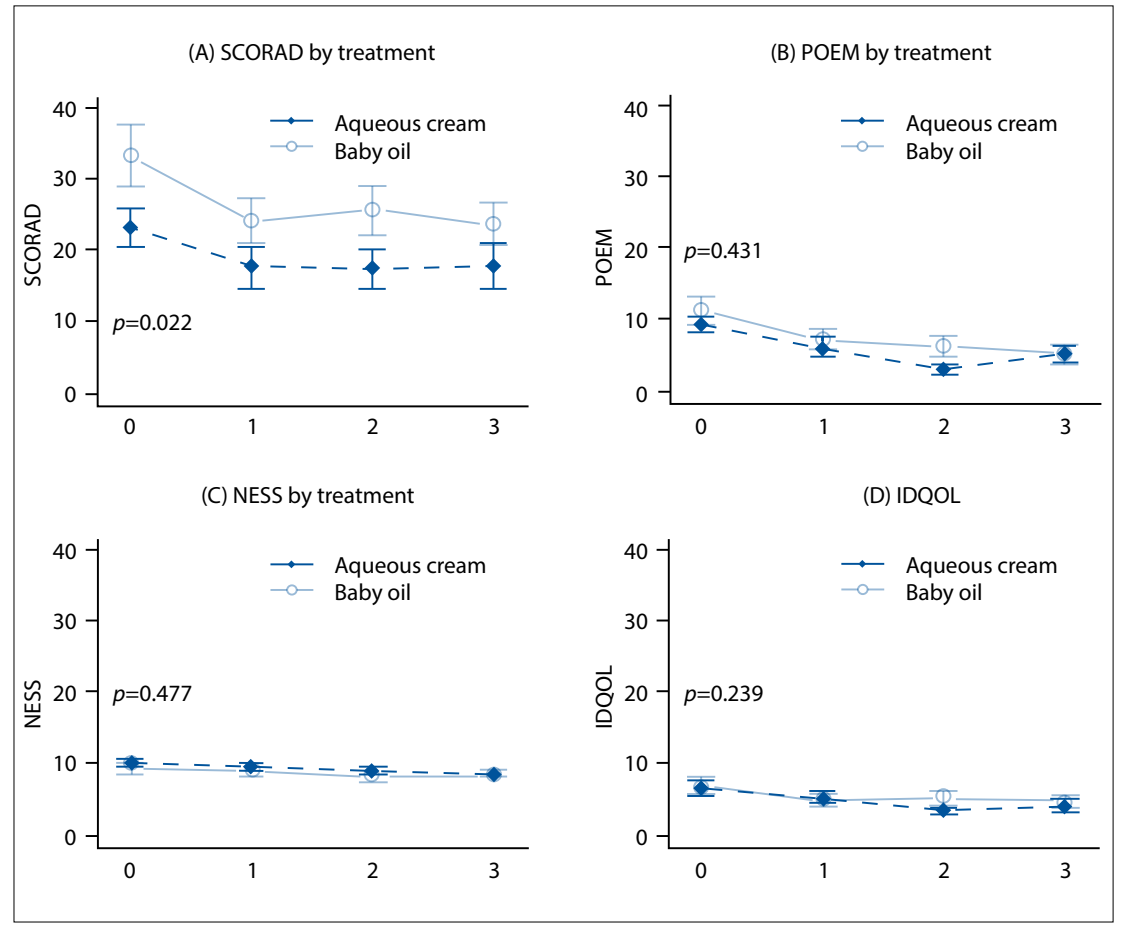

Fig. 2. Interaction plots of treatment by time (aqueous cream $v$. baby oil) in study 1 . The y-axes show means at each time point. All the scores tend to decline over time for all the treatments. There is a significant difference between the treatments for objective SCORAD only $(\mathrm{p}=0.022)$, but this difference was also present at baseline $(\mathrm{p}=0.042)$ and is unlikely to be the result of treatment. 


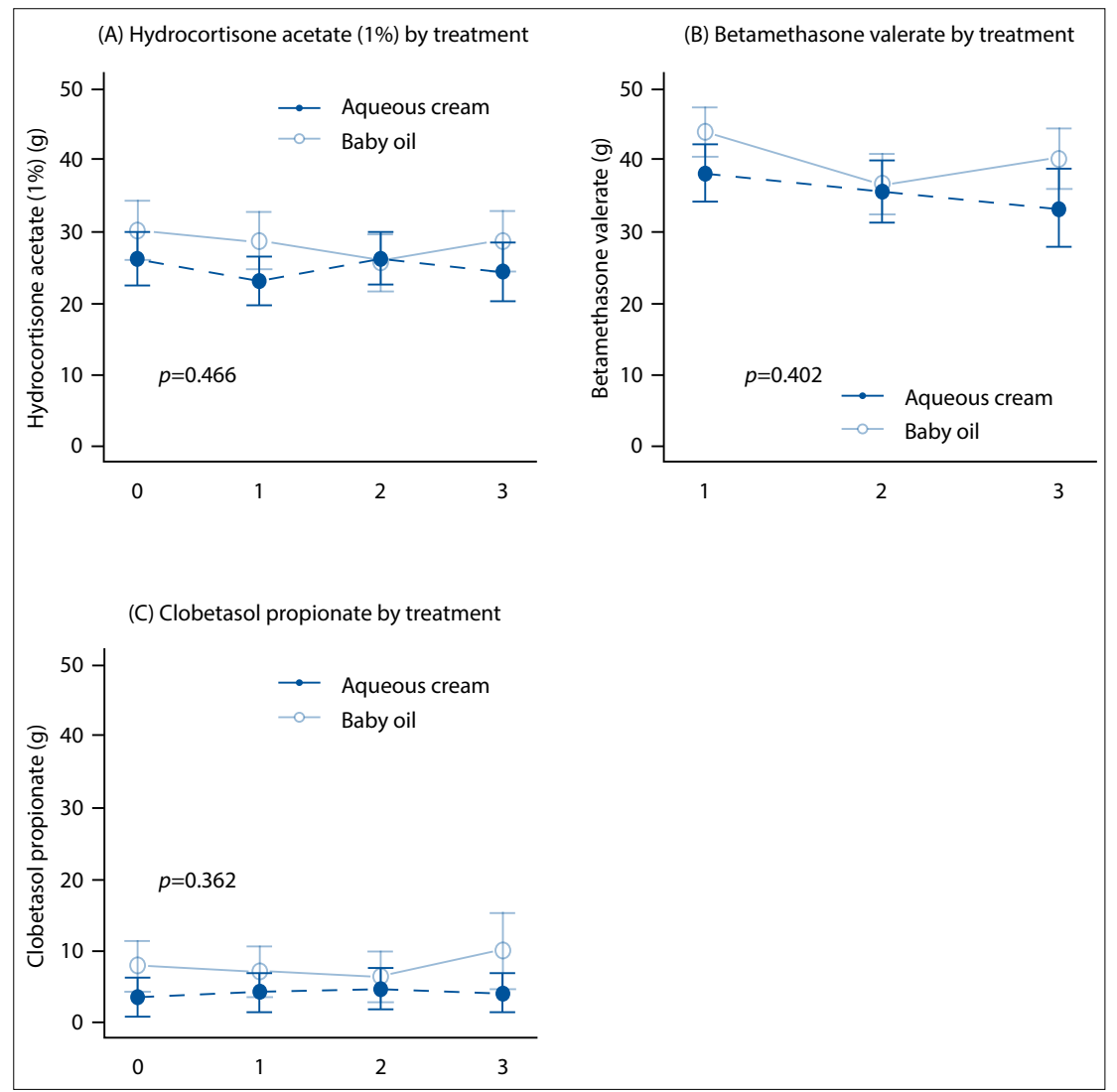

Fig. 3. Interaction plots of treatment by time (aqueous cream v. baby oil) in study 1 for amount and class strength of topical steroids used during the preceding month.

different treatments. It is noteworthy that the amount (and potency) of steroids used did not differ between groups. Scores tended to decline over time from baseline for all the four treatment groups in study 2 , suggesting that the moisturisers may be equivalent. Consistent with this finding is the IDQOL, which did not differ between groups in the two studies.

Fragrance-free baby oil baths, glycerine/ petroleum (the ' $1: 2$ moisturiser') and petroleum jelly were generally well tolerated in both studies, with only four of 100 users (one in each of four study groups) complaining of itching, which was presumed to be associated with baby oil (applied directly to the skin as a soap substitute). Fragrance-free baby oil is commonly used and well tolerated as a bath additive by patients in our unit. Although there was no statistical difference in the prevalence of side-effects between groups, the few cases of irritation with baby oil were also unexpected because it is so commonly used worldwide in healthy neonates and children as well as as a moisturiser in the formulation liquid paraffin/petroleum jelly 50:50 in AD. Liquid paraffin-based emollients may contain $1 \%$ sodium lauryl sulphate, which may irritate the skin. It was interesting that no participant complained of the shine of petroleum jelly, and that no case of (expected) occlusive folliculitis was noted. However, the petroleum jelly group did have a larger number of dropouts, although not significantly so, than the glycerine/petroleum group. A recent study has demonstrated impairment of the skin barrier function in healthy subjects using aqueous cream as a daily moisturiser; this is also thought to be the result of sodium lauryl sulphate in aqueous cream. ${ }^{[10]}$ In our unit aqueous cream is not recommended as a moisturiser, a subset of patients finding it irritating even as a soap substitute. For these patients, emulsifying ointment or fragrancefree baby oil have been acceptable soap substitutes.

Moisturisers are important as maintenance treatment and for prevention of flares in $\mathrm{AD}$. Several clinical trials have shown that moisturisers can lessen the symptoms and signs of $\mathrm{AD}$ and enhance the effects of, as well as reduce the amount of, topical corticosteroids needed for disease control. ${ }^{[1,20-21]}$ Recently published studies tend to focus on new agents without comparing them with available treatments for AD. Despite a myriad of moisturiser choices in the literature, uncertainty as to which one to

Patients with $\mathrm{AD}$ constitute the largest single diagnosis in paediatric dermatology choose remains. clinics (including SA 59\%, London 36\%, Greece 35\% and Hong Kong 33\%) in 19 studies from 16 countries. ${ }^{[1]}$ Families of $\mathrm{AD}$ sufferers in poor settings become increasingly dependent on public health services, increasing pressure on public healthcare facilities. Although cetomacrogol and emulsifying ointment are considered inexpensive in Western countries, they are not affordable for most of our patients, who have easy access to but do not use petroleum jelly and baby oil, depending instead on government clinic suppliers. Even in wellresourced countries, spiralling medical costs have increased the demand for evidencebased cost-effective treatments. Results from this prospective controlled study revealed that more affordable moisturisers are effective alternatives for AD.

\section{Study limitations}

The small sample size is a limitation to this study, although calculations were adequately powered to detect differences in groups (at 20 and 22 participants per group in studies 1 and 2, respectively). However, it was only noticed towards the end of the study that 20 instead of 22 participants per group had also (erroneously) been recruited for study 2. Loss to follow-up was minimal, with retention of $92 \%$ of participants to the end of the study at 12 weeks - a longer duration of follow-up than in most $\mathrm{AD}$ moisturiser studies. ${ }^{[20,22-24]}$

\section{Conclusion}

This study suggests that affordable moisturisers are effective in the management of $\mathrm{AD}$. The small sample size and single-centre setting limit generalisability. Fragrance-free baby oil is an alternative soap substitute, but may be better tolerated as a bath additive. Glycerine/petroleum (the '1:2 moisturiser') may be preferred to petroleum jelly, but both are equivalent to standard moisturisers (cetomacrogol and emulsifying ointment) in mild to moderate AD. Use of accessible and affordable moisturisers could help empower families to better manage and reduce the cost of treating $\mathrm{AD}$.

Acknowledgements. We are grateful to the participating families. The study was investigator initiated, and all emollients were requested from and donated by Sekpharma (SA), a generic medicine supply company.

\section{References}

1. Eichenfield LF, Tom WL, Berger TG, et al. Guidelines of care for the management of atopic dermatitis: Section 2. Management and treatment of atopic dermatitis with topical therapies. J Am Acad Dermatol 2014;71(1):116-132. [http://dx.doi. org/10.1016/.j.jaad.2014.03.023] 
2. Draelos ZD. An evaluation of prescription device moisturizers. J Cosmet Dermatol 2009;8(1):40-43. [http://dx.doi.org/10.1111/j.1473-2165.2009.00422.x]

3. Chamlin SL, Kao J, Frieden IJ, et al. Ceramide-dominant barrier repair lipids alleviate childhood atopic dermatitis: Changes in barrier function provide a sensitive indicator of disease activity. J Am Acad Dermatol 2002;47(2):198-208. [http://dx.doi.org/10.1067/mjd.2002.124617]

4. Eberlein B, Eicke C, Reinhardt HW, Ring J. Adjuvant treatment of atopic eczema: Assessment of an emollient containing N-palmitoylethanolamine (ATOPA study). J Eur Acad Dermatol Venereol 2008;22(1):73-82. [http://dx.doi.org/10.1111/j.1468-3083.2007.02351.x]

5. Sugarman JL, Parish LC. Efficacy of a lipid-based barrier repair formulation in moderate-to-severe pediatric atopic dermatitis. J Drugs Dermatol 2009;8(12):1106-1111

6. Morren MA, Przybilla B, Bamelis M, Heykants B, Reynaers A, Degreef H. Atopic dermatitis: Triggering factors. J Am Acad Dermatol 1994;31(3):467-473. [http://dx.doi.org/10.1016/S0190-9622(94)70213-6]

7. Miller DW, Yentzer BA, Clark AR, et al. An over-the-counter moisturizer is as clinically effective as, and more cost-effective than, prescription barrier creams in the treatment of children with mild-tomoderate atopic dermatitis: A randomized, controlled trial. J Drugs Dermatol 2011;10(5):531-537.

8. Asher MI, Montefort S, Bjorksten B, et al. Worldwide time trends in the prevalence of symptoms of asthma, allergic rhinoconjunctivitis and eczema in childhood. ISAAC Phases One and Three repert asthma, allergic rhinoconjunctivis, and eczema in childhood. SAAC Phases One and Three repeat multicountry cross-sect

9. Chalmers DA, Todd G, Saxe N, et al. Validation of the U.K. Working Party diagnostic criteria for atopic eczema in a Xhosa-speaking African population. Br J Dermatol 2007;156(1):111-116. [http://dx.doi. eczema in a Xhosa-speaking African po
org/10.1111/j.1365-2133.2006.07606.x]

org/10.1111/j.1365-2133.2006.07606.x]
10. Danby SG, Al-Enezi T, Sultan A, Chittock J, Kennedy K, Cork MJ. The effect of aqueous cream $\mathrm{BP}$ on the skin barrier in volunteers with a previous history of atopic dermatitis. Br J Dermatol 2011;165(2):329-334. [http://dx.doi.org/10.1111/j.1365-2133.2011.10395.x]

11. Kakande B, Gumedze F, Hlela C, Khumalo NP. The top ten diagnoses could reduce referrals to paediatric dermatology clinics. Paediatric Dermatology 2015 (in press).

12. Moncrieff G, Cork M, Lawton S, Kokiet S, Daly C, Clark C. Use of emollients in dry-skin conditions: Consensus statement. Clin Exp Dermatol 2013;38(3):231-238; quiz 238. [http://dx.doi.org/10.1111/ ced.12104]

13. McHenry PM, Williams HC, Bingham EA. Management of atopic eczema. Joint Workshop of the British Association of Dermatologists and the Research Unit of the Royal College of Physicians of London. BMJ 1995;310(6983):843-847. [http://dx.doi.org/10.1136/bmj.310.6983.843]

14. Proksch E, Lachapelle JM. The management of dry skin with topical emollients - recent perspectives. J Dtsch Dermatol Ges 2005;3(10): 768-774. [http://dx.doi.org/10.1111/j.1610-0387.2005.05068.x]
15. Bissonnette R, Maari C, Provost N, et al. A double-blind study of tolerance and efficacy of a new ureacontaining moisturizer in patients with atopic dermatitis. J Cosmet Dermatol 2010;9(1):16-21. [http:// dx.doi.org/10.1111/j.1473-2165.2010.00476.x]

16. Wiren K, Nohlgard C, Nyberg F, et al. Treatment with a barrier-strengthening moisturizing cream delays relapse of atopic dermatitis: A prospective and randomized controlled clinical trial. J Eur Acad Dermatol Venereol 2009;23(11):1267-1272. [http://dx.doi.org/10.1111/j.1468-3083.2009.03303.x]

17. Williams HC, Pembroke AC, Hay RJ. The UK working party's diagnostic criteria for atopic dermatitis 1ll: Independent hospital validation. Br J Dermatol 1994;131(3):406-416. [http://dx.do org/10.1111/j.1365-2133.1994.tb08532.x]

18. Stata Corp. Stata Statistical Software: Release 13. College Station, TX: StataCorp LP, 2013.

19. Foundation for Statistical Computing. A Language and Environment for Statistical Computing. Vienna, Austria: R Foundation for Statistical Computing, 2013. http://www.R-project.org/ (accessed 2012)

20. Breternitz M, Kowatzki D, Langenauer M, Elsner P, Fluhr JW. Placebo-controlled, double-blind, randomized, prospective study of a glycerol-based emollient on eczematous skin in atopic dermatitis: Biophysical and clinical evaluation. Skin Pharmacol Physiol 2008:21(1):39-45. [http.//dxdoi. org/10.1159/000111134]

21. Msika P, de Belilovsky C, Piccardi N, Chebassier N, Baudouin C Chadoutaud B. New emollien with topical corticosteroid-sparing effect in treatment of childhood atopic dermatitis: SCORAD and quality of life improvement. Pediatr Dermatol 2008:25(6):606-612. [http://dx.doi.org/10.1111/j.1525quality of life impro

22. Hoare C, Li Wan Po A, Williams H. Systematic review of treatments for atopic eczema. Health Techno Assess 2000;4(37):1-191. [http://dx.doi.org/10.3310/hta4370]

23. Hanifin JM, Hebert AA, Mays SR, et al. Effects of a low-potency corticosteroid lotion plus a moisturizin regimen in the treatment of atopic dermatitis. Current Therapeutic Research 1998;59(4):227-233. [http://dx.doi.org/10.1016/S0011-393X(98)85076-5]

24. Korting HC, Schollmann C, Cholcha W, Wolff L, Collaborative Study Group. Efficacy and tolerability of pale sulfonated shale oil cream $4 \%$ in the treatment of mild to moderate atopic eczema in children: A multicentre, randomized vehicle-controlled trial. J Eur Acad Dermatol Venereol 2010;24(10):11761182. [http://dx.doi.org/10.1111/j.1468-3083.2010.03616.

Accepted 1 July 2015. 